\title{
Cholesterol Biosynthesis Supports Myelin Gene Expression and Axon Ensheathment through Modulation of P13K/Akt/ mTor Signaling
}

\author{
-Emily S. Mathews and $\odot$ Bruce Appel \\ Department of Pediatrics, University of Colorado School of Medicine, Aurora, Colorado 80045
}

\begin{abstract}
Myelin, which ensheaths and insulates axons, is a specialized membrane highly enriched with cholesterol. During myelin formation, cholesterol influences membrane fluidity, associates with myelin proteins such as myelin proteolipid protein, and assembles lipid-rich microdomains within membranes. Surprisingly, cholesterol also is required by oligodendrocytes, glial cells that make myelin, to express myelin genes and wrap axons. How cholesterol mediates these distinct features of oligodendrocyte development is not known. One possibility is that cholesterol promotes myelination by facilitating signal transduction within the cell, because lipid-rich microdomains function as assembly points for signaling molecules. Signaling cascades that localize to cholesterol-rich regions of the plasma membrane include the PI3K/Akt pathway, which acts upstream of mechanistic target of rapamycin (mTOR), a major driver of myelination. Through manipulation of cholesterol levels and PI3K/Akt/mTOR signaling in zebrafish, we discovered that mTOR kinase activity in oligodendrocytes requires cholesterol. Drawing on a combination of pharmacological and rescue experiments, we provide evidence that mTOR kinase activity is required for cholesterol-mediated myelin gene expression. On the other hand, cholesterol-dependent axon ensheathment is mediated by Akt signaling, independent of mTOR kinase activity. Our data reveal that cholesterol-dependent myelin gene expression and axon ensheathment are facilitated by distinct signaling cascades downstream of Akt. Because mTOR promotes cholesterol synthesis, our data raise the possibility that cholesterol synthesis and mTOR signaling engage in positive feedback to promote the formation of myelin membrane.
\end{abstract}

Key words: cholesterol; mTOR; myelin; oligodendrocyte; zebrafish

Significance Statement

The speed of electrical impulse movement through axons is increased by myelin, a specialized, cholesterol-rich glial cell membrane that tightly wraps axons. During development, myelin membrane grows dramatically, suggesting a significant demand on mechanisms that produce and assemble myelin components, while it spirally wraps axons. Our studies indicate that cholesterol is necessary for both myelin growth and axon wrapping. Specifically, we found that cholesterol facilitates signaling mediated by the $\mathrm{PI} 3 \mathrm{~K} / \mathrm{Akt} / \mathrm{mTOR}$ pathway, a powerful driver of myelination. Because mTOR promotes the expression of genes necessary for cholesterol synthesis, cholesterol formation and PI3K/Akt/mTOR signaling might function as a feedforward mechanism to produce the large amounts of myelin membrane necessary for axon ensheathment.

\section{Introduction}

Myelin is a specialized membrane that tightly wraps axons, thereby providing electrical insulation and promoting rapid sal-

Received March 4, 2016; revised May 9, 2016; accepted June 6, 2016.

Author contributions: E.S.M. and B.A. designed research; E.S.M. performed research; E.S.M. analyzed data; E.S.M. and B.A. wrote the paper.

This work was supported by National Institutes of Health (NIH) Grants NS-04668 and NS-095679 (to B.A.), NIH/National Center for Advancing Translational Sciences Colorado Clinical and Translational Science Award TL1-TR001081 (to E.S.M.), and the Gates Frontiers Fund. The University of Colorado Anschutz Medical Campus Zebrafish Core Facility was supported by NIH Grant P30-NS-048154. We thank members of the Appel laboratory and Wendy Macklin for discussions, and Peter Vogt for the gift of the myrAKT plasmid.

The authors declare no competing financial interests. tatory conduction of nerve impulses. The unique functional properties of myelin result from its unique composition of myelin-specific proteins, glycosphingolipids, and cholesterol (Morell and Quarles, 1999). In particular, myelin is highly enriched for cholesterol (Morell and Jurevics, 1996), accounting for up to $80 \%$ of brain cholesterol in adults (Muse et al., 2001; Dietschy and Turley, 2004). Cholesterol influences membrane permeability and fluidity (Brûlet and McConnell, 1976; Cooper,

Correspondence should be addressed to Bruce Appel, University of Colorado Anschutz Medical Campus, MS 8108 Aurora, C0 80045. E-mail: bruce.appel@ucdenver.edu.

DOI:10.1523/JNEUROSCI.0726-16.2016

Copyright $\odot 2016$ the authors $\quad 0270-6474 / 16 / 367628-12 \$ 15.00 / 0$ 
1978; $\mathrm{Xu}$ and London, 2000) and binds to myelin proteins (Krämer-Albers et al., 2006), thereby facilitating membrane compaction (Saher et al., 2011).

Cholesterol is also required by oligodendrocytes, the myelinating glial cells of the CNS, to express myelin genes and wrap axons with myelin membrane. Conditional mutation of squalene synthase, an enzyme required for cholesterol synthesis, in oligodendrocytes reduced levels of myelin proteins in the brain and spinal cord (Saher et al., 2005). Pharmacological inhibition of cholesterol synthesis in vitro using statins, inhibitors of cholesterol synthesis and protein isoprenylation, reduced the expression of myelin gene transcripts and proteins (Smolders et al., 2010). Consistent with this, mutation of hmgcs1, which encodes an enzyme necessary for isoprenoid and cholesterol synthesis, in zebrafish caused deficits of myelin gene expression and axon ensheathment (Mathews et al., 2014).

How might cholesterol facilitate myelin gene expression and axon ensheathment? One possibility is that cholesterol promotes myelination by enabling signal transduction within the cell through formation of membrane microdomains. Membrane microdomains are defined as small, heterogeneous, highly dynamic, sterol-, sphingolipid-, and glycerophosphatidylinositol-anchored proteinenriched domains (Pike, 2006). Membrane microdomains function as signaling platforms because they localize receptors for many key signaling cascades (Hoessli et al., 2000; Simons and Toomre, 2000). For example, the receptor tyrosine kinases (RTKs) PDGF receptor- $\alpha$ and ErbB, which promote oligodendrocyte differentiation and myelination, localize to membrane microdomains (Nagy et al., 2002; Decker and ffrench-Constant, 2004). RTKs can activate myelinpromoting signaling pathways, including the MEK/Erk pathway (McKay and Morrison, 2007) and the PI3K/Akt/mammalian target of rapamycin (mTOR) pathway (Laplante and Sabatini, 2009). This raises the possibility that the myelination deficit in cholesteroldeficient animals results, in part, from failure to assemble and activate myelin-promoting RTKs that drive key developmental signaling pathways.

Here we show that the cholesterol biosynthetic pathway promotes myelin membrane growth and axon ensheathment by facilitating PI3K/Akt/mTOR signaling. In particular, we provide evidence that mTOR kinase activity in oligodendrocyte precursor cells (OPCs) requires cholesterol, and that mTOR kinase activity is required for cholesterol-dependent myelin gene expression. Furthermore, cholesterol promotes axon ensheathment, at least in part, via Akt signaling independently of mTOR kinase activity. Additionally, we reveal a role of mTOR signaling in regulating myelin sheath growth. By contrast, we find little evidence that cholesterol-dependent Erk signaling promotes myelination. Because mTOR signaling also drives the production of lipids, including cholesterol, our data provide a mechanistic explanation for the tremendous growth of myelin membrane necessary for axon ensheathment.

\section{Materials and Methods}

Ethics statement. The animal work in this study was approved by the Institutional Animal Care and Use Committee of the University of Colorado School of Medicine.

Zebrafish lines and husbandry. Embryos were raised at $28.5^{\circ} \mathrm{C}$ in egg water or embryo medium (EM) and staged according to hours postfertilization (hpf), days postfertilization (dpf), and morphological criteria (Kimmel et al., 1995). hmgcs $1^{\text {vu57 }}$ (Mathews et al., 2014), Tg(olig2: EGFP) $)^{\text {vul2 }}$ (Shin et al., 2003), $\operatorname{Tg}(n k x 2.2 a: E G F P-C a a X)^{\text {vul }}$ (Kirby et al., 2006; Kucenas et al., 2008), $\operatorname{Tg}(\text { sox10:GAL4-VP16, cmlc2:Cerulean })^{\text {co19, }}$, and $\operatorname{Tg}(4 x n r U A S: E G F P-C a a X, c m l c 2: E G F P)^{c o 18}$ (Mathews et al., 2014) fish were used for this study. Animals of either sex were used.
In situ RNA hybridization and immunohistochemistry. Myelin basic protein a (mbpa; Brösamle and Halpern, 2002) RNA probes were generated using digoxigenin RNA labeling kits (Roche). In situ RNA hybridization was performed as described previously (Hauptmann and Gerster, 2000). For immunohistochemistry, larvae were fixed using $4 \%$ paraformaldehyde. We used rabbit anti-phospho-S6 ribosomal protein (Ser240/244; 1:100; catalog \#2215S, Cell Signaling Technology), rabbit anti-Phospho-p44/42 MAPK (Erk1/2; Thr202/Tyr204; 1:100; catalog \#4377S, Cell Signaling Technology), and mouse anti-GFP (1:100; catalog \#A11120, Life Technologies) as primary antibodies. For fluorescent detection of antibody labeling, we used Alexa Fluor 568 goat anti-rabbit and Alexa Fluor 488 goat anti-mouse conjugates (1:200; Life Technologies). In situ hybridization images were collected using a QImaging Retiga Exi color CCD camera mounted on a compound microscope. Optical sections from $z$-stack datasets were merged in Helicon Focus, and maximum projections were imported into Adobe Photoshop. Image manipulations were limited to levels, curve, and contrast adjustments. Fluorescence images were collected using a Zeiss Axiovert 200 microscope equipped with a PerkinElmer spinning disk confocal system and Volocity software (PerkinElmer) and imported into Adobe Photoshop.

Constitutively active Akt expression experiments. psox10:myrAKT-2AEGFP-CaaX was created by subcloning myrAKT from $p B S F I-m y r-a k t-$ T308D/S473D (Aoki et al., 1998; plasmid \#49192, Addgene), into $p M E$, which was then used for recombination with $p 5 E-$ sox $10, p 3 E-2 A-E G F P$ CaaX, and pDest-cmlc2-GFP using the Tol2 kit (Kwan et al., 2007). A solution containing $25 \mathrm{ng} / \mu \mathrm{l}$ the resulting plasmid, $0.4 \mathrm{M} \mathrm{KCl}$, and phenol red was injected into newly fertilized eggs. Larvae were sorted by cardiac GFP expression, driven by the cmlc2-GFP reporter included in the plasmid, and imaged using a confocal microscope.

Drug inhibitor and rescue experiments. Rapamycin (catalog \#R5000, LC Laboratories), Ro 48-8071 (catalog \#10006415, Cayman Chemical), and U-0126 (catalog \#70970, Cayman Chemical) were each dissolved in $100 \%$ DMSO at a concentration of $10 \mathrm{~mm}$. Drugs were diluted in EM to make the following working concentrations: rapamycin $10 \mu \mathrm{M}$, Ro 48$8071,2.25 \mu \mathrm{M}$, and U-0126 $30 \mu \mathrm{M}$. Each drug had a final concentration of $0.2 \%$ DMSO, and $0.2 \%$ DMSO in EM was used as a control solution. Drug treatments were initiated at $24 \mathrm{hpf}$ (Ro 48-8071) and $55 \mathrm{hpf}$ (U0126, rapamycin) and replaced with fresh drug every $24 \mathrm{~h}$. Water-soluble cholesterol (MP Biomedicals) was dissolved in water at a concentration of $10 \mathrm{mg} / \mathrm{ml}$ and then diluted in water to a working concentration of 1 $\mathrm{mg} / \mathrm{ml}$. A total of 2-3 $\mathrm{nl}$ of cholesterol was pressure injected into the yolk of 24 hpf embryos.

Morpholino oligonucleotide injections. To reduce ptena levels, we injected $1.6 \mathrm{ng}$ of a morpholino oligonucleotide (MO; GeneTools) designed to block the translation start site of ptena mRNA (Croushore et al., 2005) into a single cell of newly fertilized embryos. MO targeting the tp53 gene was included in the injection solution to reduce cell lethality resulting from MO off-target effects (Robu et al., 2007).

Cell number, sheath quantification, and statistical analysis. To determine the number of phosphorylated-ribosomal protein $6\left(\mathrm{pS}^{+}\right)$and pERK $^{+}$dorsal OPCs in Figures 1 and 3, three consecutive images in the trunk spinal cord above the yolk extension were collected for each larva using the PerkinElmer spinning disk confocal. The number of $\mathrm{pS}^{+}$or $\mathrm{pERK}^{+}$dorsal OPCs per field was quantified within Volocity software. We focused on olig2:EGFP ${ }^{+}$cells in dorsal spinal cord, which are exclusively OPCs. $n k x 2.2 a$ :EGFP-CaaX ${ }^{+}$cells were analyzed from the dorsal spinal cord above the yolk extension in Figures 5 and 6. Both dorsal and ventral sox10:myrAKT-2A-EGFP-CaaX ${ }^{+}$and sox10:EGFP-CaaX ${ }^{+}$cells were imaged from above the yolk extension in Figure 5. In Figures 6 and 7 , we measured the number and length of all nascent sheaths for each oligodendrocyte imaged. To ensure that all myelin segments emanated from a single soma and not neighboring oligodendrocytes, we analyzed only isolated oligodendrocytes with no labeled cells in adjacent segments. Sheath length was averaged per oligodendrocyte and then averaged between all cells collected per condition. Total sheath length was calculated per oligodendrocyte and then averaged between all cells collected per condition. We plotted all data and performed all statistical analyses in GraphPad Prism software (version 6). All data are expressed as the mean \pm SEM. For statistical analysis, we first performed the D'Agonstino and Pearson omnibus normality test to address normality. We assessed 


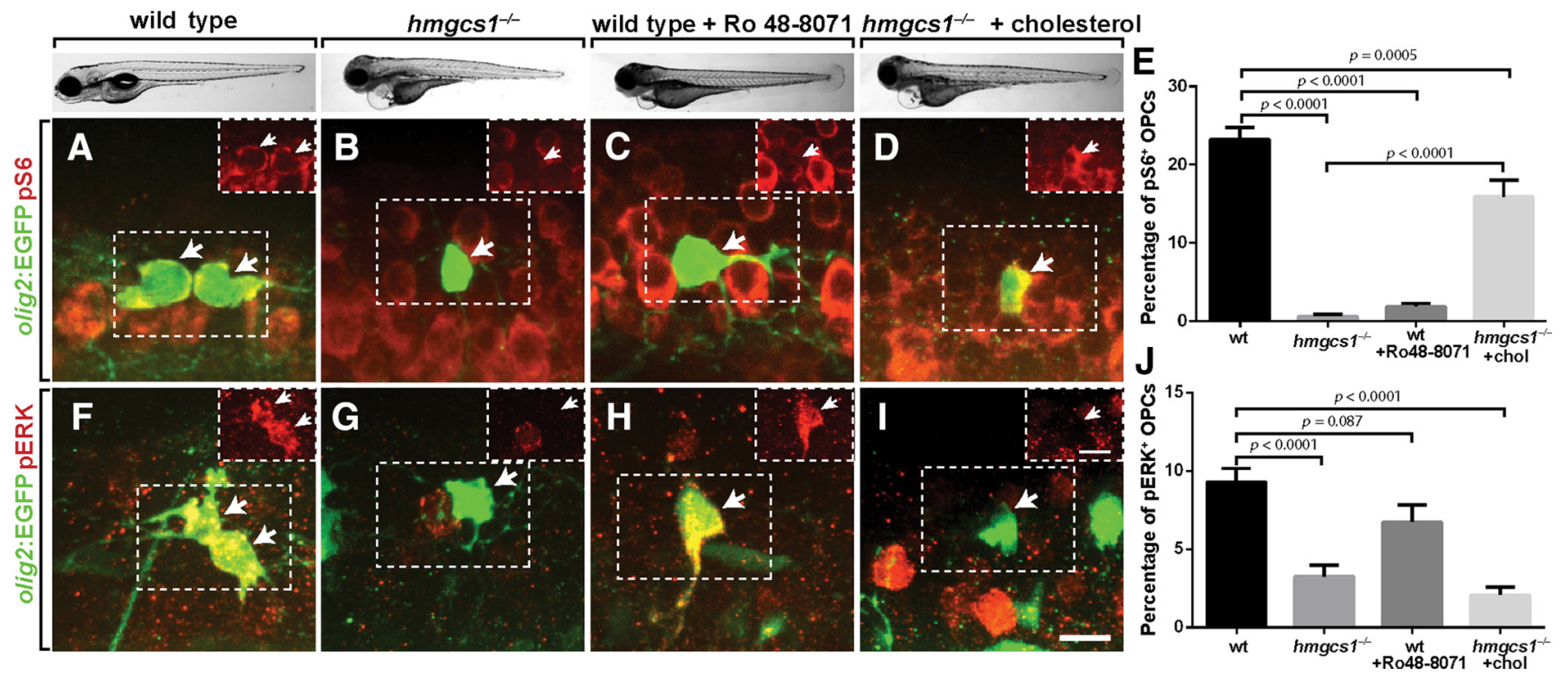

Figure 1. Loss of $h m g c s 1$ function and cholesterol alter mTOR and Erk signaling in OPCS. Representative images of living larvae 4 dpf are included for each condition. $A-D$, Representative single optical sections selected from z-stack datasets, focused from a lateral position at the trunk spinal cord, of $4 \mathrm{dpf} \mathrm{Tg}$ (oligz:EGFP) larvae labeled with antibodies to detectpS6 (red) and GFP (green). Insets show only the red channel for outlined areas. $A$, Image showing two $\mathrm{pS} 6^{+} \mathrm{OPCS}$ (arrows) in a wild-type larva. B, C, Images of pS6 ${ }^{-}$OPCs (arrows) in $h m g c s 1$ mutant larva and wild-type larva treated with R0-48-8071 to block cholesterol synthesis. $\boldsymbol{D}, \mathrm{pS} 6^{+} \mathrm{OPC}$ of an $h m g c s 1$ mutant larva injected with cholesterol. $E$, Graph showing percentages of dorsal pS6 ${ }^{+} 0 \mathrm{PCs}(n=$ at least 21 larvae for each genotype and treatment; $p$ values were calculated using a Mann-Whitney test). $F-I$, Representative single-optical section images, viewed from a lateral position, obtained from $4 \mathrm{dpf} T g(0$ lig2:EGFP) larvae labeled with antibodies to detect pErk (red) and GFP (green). $\boldsymbol{F}$, Example of pErk ${ }^{+} \mathrm{OPC}$ in a wild-type larva. G, pErk ${ }^{-}$OPC in a $h m g c s 1$ mutant larva. $\boldsymbol{H}$, Example of a pErk ${ }^{+}$OPC in a wild-type larva treated with Ro 48-8071. I, pErk ${ }^{-}$OPC of an $h m g c s 1$ mutant larva injected with cholesterol. J, Graph showing the percentages of pErk ${ }^{+}$dorsal OPCs $(n=$ at least 20 larvae for each genotype and treatment; $p$ values were calculated using a Mann-Whitney test). Error bars represent the SEM. Scale bars, $10 \mu \mathrm{m}$.

statistical significance using the nonparametric Mann-Whitney test because the data analyzed did not meet the assumption of normality require for a Student's two-tailed $t$ test.

\section{Results}

\section{mTOR kinase activity in OPCs requires cholesterol}

We showed previously that zebrafish larvae deficient in cholesterol production express myelin genes at much lower levels than normal (Mathews et al., 2014). Because cholesterolenriched membrane microdomains are assembly points for signaling molecules (Hoessli et al., 2000; Simons and Toomre, 2000), we speculated that severe cholesterol deficiency could disrupt the transduction of signals that promote myelination. We chose the PI3K/Akt/mTOR pathway as a candidate for investigation, because it potently drives myelination in mice and zebrafish (Flores et al., 2008; Narayanan et al., 2009; Tyler et al., 2009; Sherman et al., 2012; Bercury et al., 2014; Wahl et al., 2014; Kearns et al., 2015). To investigate PI3K/Akt/mTOR signaling, we used pS6 as an assay for mTOR kinase activity. We labeled whole $4 \mathrm{dpf} \mathrm{Tg}$ (olig2:EGFP) zebrafish larvae with antibody to detect pS6 in OPCs. In wild-type larvae, $\sim 25 \%$ of dorsal spinal cord OPCs were $\mathrm{pS}^{+}{ }^{+}$(Fig. $1 \mathrm{~A}, \mathrm{E}$ ). By contrast, only $0.6 \%$ of dorsal OPCs were $\mathrm{pS}^{+}{ }^{+}$in $\mathrm{hmgcs} 1$ mutant larvae, which are deficient for Hmgcs1, an enzyme required for cholesterol biosynthesis (Fig. $1 B, E$ ). Treatment of wild-type larvae with Ro 48-8071, an oxidosqualene cyclase inhibitor (Morand et al., 1997) that blocks cholesterol synthesis, similarly reduced the fraction of dorsal $\mathrm{pS}^{+}$OPCs (Fig. 1C,E). Injection of soluble cholesterol into $h m g c s 1$ mutant larvae partially rescued pS6 labeling of OPCs (Fig. $1 D, E$ ), verifying that the reduced mTOR activity in OPCs of $h m g c s 1$ mutant larvae results, at least in part, from a deficit of cholesterol. These data indicate that mTOR kinase activity in OPCs requires cholesterol.
Another candidate signal transduction system is the MEK/Erk pathway because it also promotes myelin production in mice and in vitro (Fyffe-Maricich et al., 2011, 2013; Guardiola-Diaz et al., 2012; Ishii et al., 2012, 2013). We therefore evaluated MEK signaling activity by performing immunohistochemistry to detect pErk. In wild-type larvae, $\sim 9 \%$ of dorsal OPCs had active Erk signaling (Fig. $1 F, J$ ), whereas only 3\% of dorsal OPCs in hmgcs 1 mutant larvae were pErk ${ }^{+}$(Fig. 1G,J). Ro 48-8071 treatment of wild-type larvae reduced the percentage of dorsal pErk ${ }^{+}$OPCs just slightly to $7 \%$ (Fig. $1 \mathrm{H}, \mathrm{J}$ ). However, the injection of soluble cholesterol into hmgcsl mutant larvae did not increase the fraction of dorsal pErk ${ }^{+}$OPCs (Fig. 1I,J). Thus, although Hmgcs1 function promotes Erk activity in OPCs, this role appears to be largely independent of its role in cholesterol synthesis. One possible explanation is that Hmgcs1-dependent Erk signaling requires isoprenoid biosynthesis, because the hmgcs1 mutation disrupts both the cholesterol and isoprenoid biosynthetic pathways (Mathews et al., 2014). Together, these results are consistent with the possibility that $\mathrm{PI} 3 \mathrm{~K} / \mathrm{Akt} / \mathrm{mTOR}$ signaling promotes cholesterol-dependent myelin gene expression and suggest that changes in MEK/Erk signaling in oligodendrocytes of hmgcs1 mutant larvae do not result from cholesterol deficiency.

\section{Cholesterol promotes myelin gene expression via mTOR signaling and not through Erk signaling}

Consistent with our previous results (Mathews et al., 2014), $h m g c s 1$ mutant larvae expressed RNA encoded by the mbpa and proteolipid protein 1 a (plp1a) genes at very low levels, whereas mutant larvae injected with cholesterol expressed $m b p a$ and plp1a at higher levels (Fig. $2 A-H$ ). Does cholesterol-dependent myelin gene expression require mTOR activity? To answer this question, we treated larvae with rapamycin, which inhibits mTOR kinase activity (Heitman et al., 1991; Brown et al., 1994; 
wild type
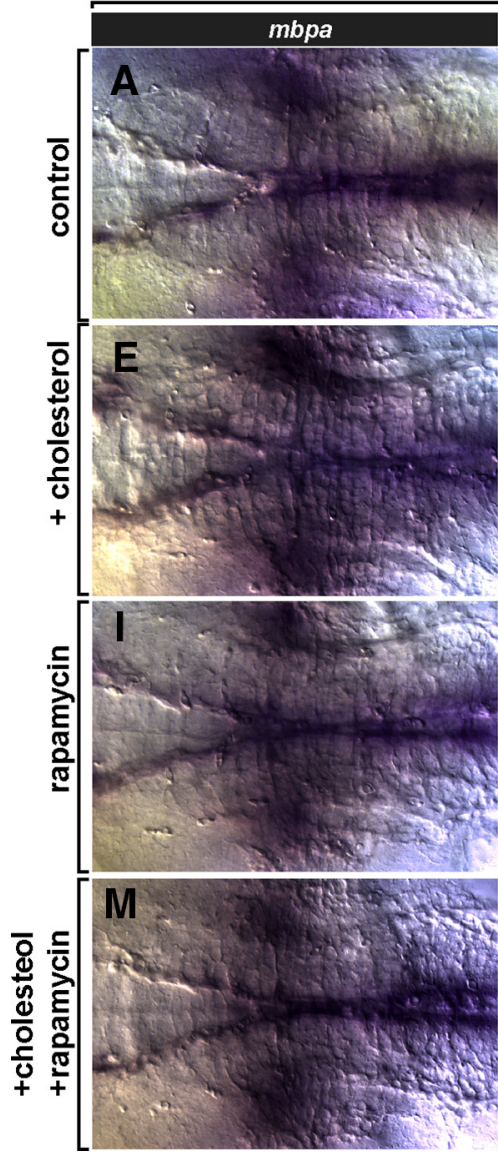
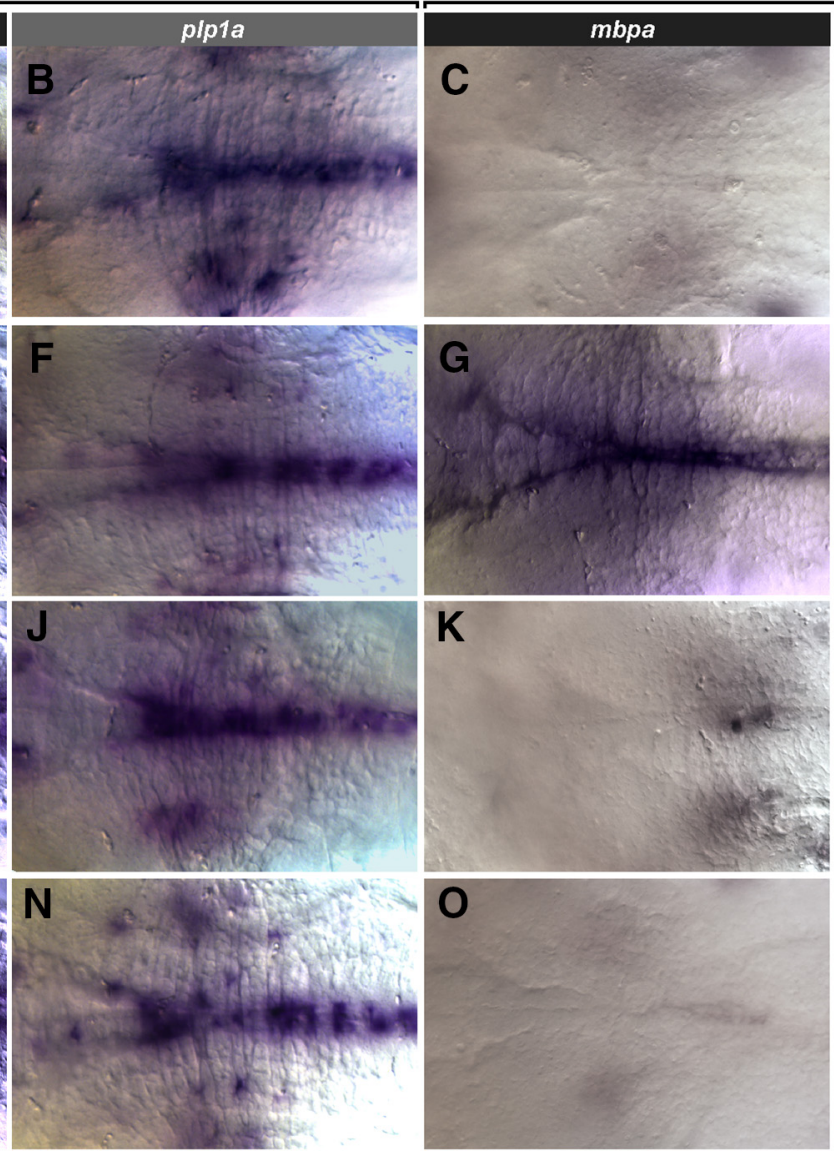

hmgcs1 ${ }^{-1}$
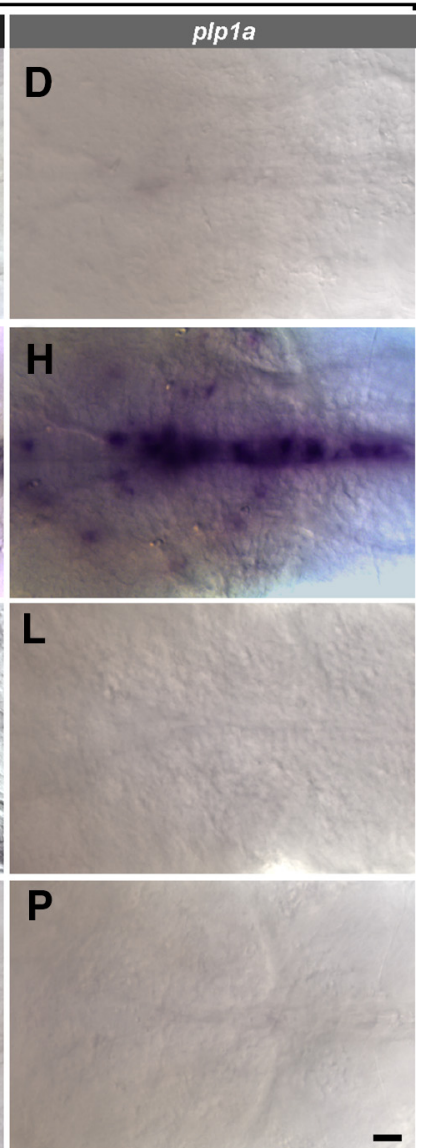

Figure 2. mTOR activity mediates cholesterol-dependent mbpa and p/p1a expression. $\boldsymbol{A}-\boldsymbol{P}$, Representative maximum projections of $z$-stack optical sections of the hindbrain, viewed from dorsal with anterior to the left, of 4 dpf larvae processed to detect mbpa and plp1a RNA. $\boldsymbol{A}, \boldsymbol{B}$, Example of mbpa ( $n=149$ of 149 larvae) and plp $1 a$ ( $n=145$ of 145 larvae) expression in a wild-type larva. $\boldsymbol{C}, \boldsymbol{D}, h m g c s 1$ mutant larvae express little mbpa ( $n=105$ of 105 larvae) and plp $1 a$ ( $n=60$ of 60 larvae). $\boldsymbol{E}$, $\boldsymbol{F}$, Wild-type larvae injected with cholesterol express mbpa ( $n=120$ of 120 larvae) and $p l p 1 a(n=83$ of 83 larvae) robustly. $\mathbf{G}, \boldsymbol{H}, h$ mgcs 1 mutant larvae injected with cholesterol have moderate to strong expression of $m b p a(n=82$ of 105 larvae) and $p / p 1 a(n=38$ of 44 larvae). $\boldsymbol{I}, \boldsymbol{J}$, Example of $m b p a(n=111$ of 111 larvae) and plp $1 a$ expression $(n=44$ of 44 larvae) in a rapamycin-treated wild-type larva. $\boldsymbol{K}, \boldsymbol{L}$, Rapamycin-treated hmgcs 1 mutant larvae express little mbpa ( $n=61$ of 61 larvae) and $p / p 1 a$ ( $n=63$ of 63 larvae). $\boldsymbol{M}, \mathbf{N}$, Wild-type larvae injected with cholesterol and treated with rapamycin express $m b p a$ ( $n=95$ of 95 larvae) and plp1a ( $n=67$ of 67 larvae). $\mathbf{0}, \boldsymbol{P}, \mathrm{hmgcs} 1$ mutant larvae injected with cholesterol and treated with rapamycin express little $m b p a(n=40$ of 40 larvae) and plp1a $(n=67$ of 67 larvae). Scale bars, $20 \mu \mathrm{m}$.

Sabatini et al., 1994; Sabers et al., 1995) and reduces myelin formation (Narayanan et al., 2009; Tyler et al., 2009; Kearns et al., 2015). Wild-type larvae treated with rapamycin expressed $m b p a$ and plp1a RNA (Fig. $2 I, J$ ), but the amount of mbpa RNA was reduced to $\sim 80 \%$ of normal (Kearns et al., 2015). As expected, rapamycin-treated $h m g c s 1$ mutant larvae expressed very little $m b p a$ and plp $1 a$ RNA (Fig. $2 K, L$ ). Notably, whereas rapamycintreated wild-type larvae injected with cholesterol expressed $m b p a$ and plp1a (Fig. $2 M, N$ ), rapamycin blocked the ability of cholesterol injection to partially rescue $m b p a$ and plp $1 a$ expression in hmgcs1 mutant larvae (Fig. 2O,P). These data indicate that mTOR activity mediates cholesterol-dependent mbpa and plp1a expression.

If mTOR transduces myelin-promoting signals that require cholesterol, then the activation of the mTOR pathway should rescue myelin gene expression in cholesterol-deficient larvae. High levels of phosphatidylinositol $(3,4,5)$-trisphosphate $\left(\mathrm{PIP}_{3}\right)$ stimulate Akt function, which activates mTOR signaling (Franke et al., 1997; Stokoe et al., 1997; Inoki et al., 2002; Manning et al., 2002). One common strategy to promote PI3K/Akt/mTOR signaling is to reduce the function of phosphatase and tensin homolog (PTEN), a phosphatase that converts $\mathrm{PIP}_{3}$ to $\mathrm{PIP}_{2}$, thereby reducing Akt activation. Accordingly, zebrafish embryos injected with antisense MOs designed to block the translation of ptena mRNA had elevated amounts of phosphorylated Akt (Croushore et al., 2005). We therefore used ptena MOs to activate PI3K/Akt/ mTOR signaling in wild-type and hmgcs1 mutant zebrafish. The frequency of $\mathrm{pS}^{+}$OPCs was increased in wild-type ptena MOinjected larvae compared with wild-type controls (Fig. $3 A, B, E$ ), and $h m g c s 1$ mutant larvae injected with ptena MO had substantially more $\mathrm{pS}^{+}$OPCs than noninjected $h m g c s 1$ mutant larvae (Fig. 3C-E). On the other hand, the proportion of $\mathrm{pErk}^{+}$dorsal OPCs did not change after ptena $\mathrm{MO}$ injection in either wild-type or hmgcsl mutant larvae (Fig. $3 F-J$ ). Therefore, ptena loss of function activates mTOR signaling, but not MEK/Erk signaling, in OPCs of hmgcs1 mutant larvae.

To test whether activation of Akt/mTOR signaling can rescue myelin gene expression in cholesterol-deficient larvae, we injected embryos with ptena MO, and assessed mbpa and plp1a expression by RNA in situ hybridization. At $4 \mathrm{dpf}$, wild-type control and ptena MO-injected wild-type larvae expressed $m b p a$ and plp1a prominently (Fig. $4 A, B, E, F$ ), whereas $h m g c s 1$ mutant larvae expressed very little $m b p a$ and plpla (Fig. 4C,G). By contrast, hmgcs 1 mutant larvae injected with ptena MO strongly expressed 

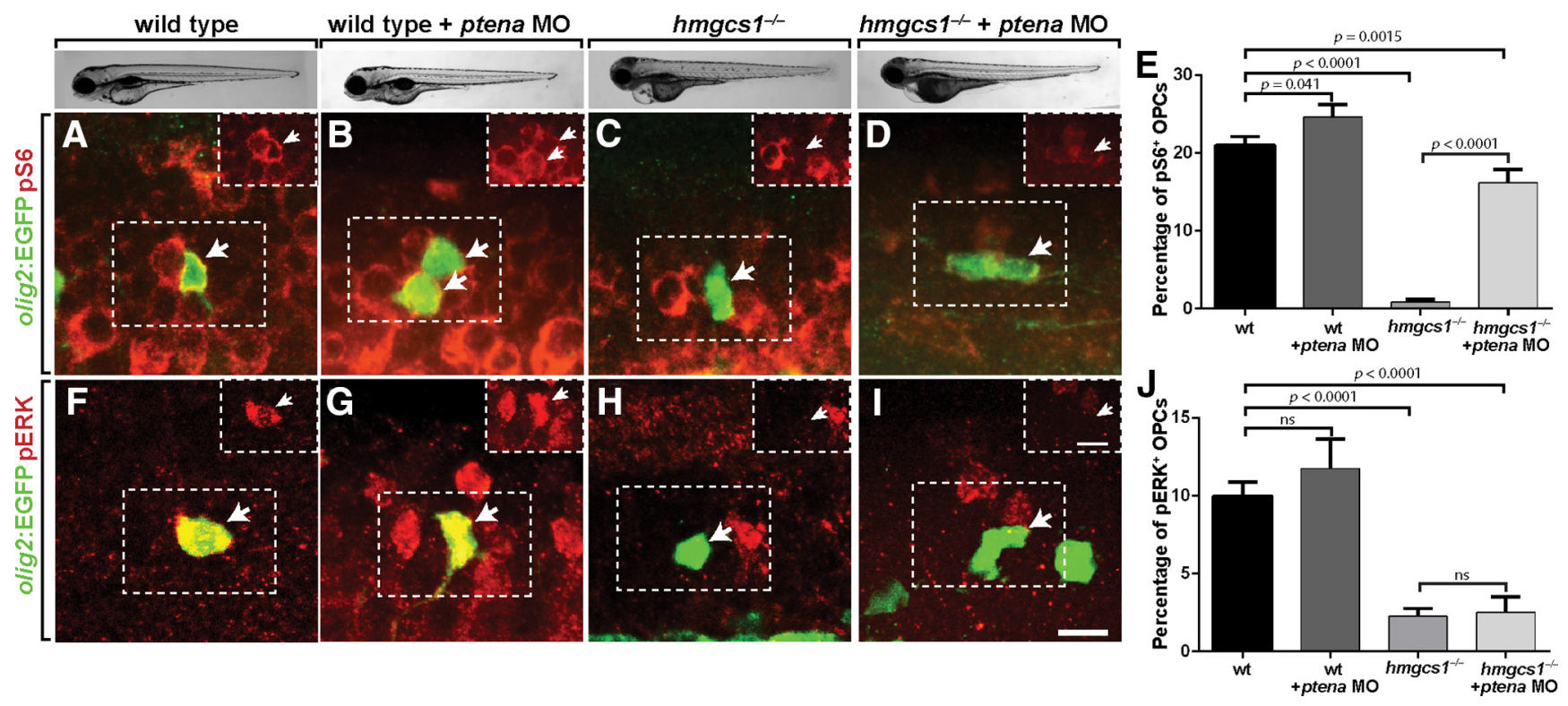

Figure 3. Inhibition of ptena restores mTOR kinase activity in the OPCs of $h m g c 51$ mutant larvae. Representative images of living 4 dpf larvae are included for each condition. $A-D$, Representative single optical sections selected from $z$-stack datasets of $4 \mathrm{dpf} T g$ (olig2:EGFP) larvae labeled with antibodies to detect pS6 (red) and GFP (green). Insets show only the red channel for outlined areas. $\boldsymbol{A}, \boldsymbol{B}$, Images of $\mathrm{pS} 6^{+} \mathrm{OPCS}$ (arrows) in wild-type larva injected with $p 53 \mathrm{MO}$ alone, as a control, and wild-type larva injected with both $p 53$ and ptena $\mathrm{M} 0$. C, Image of pS6 ${ }^{-} \mathrm{OPC}$ (arrow) in $h m g c s 1$ mutant larva injected with $p 53 \mathrm{MO} . \mathbf{D}, \mathrm{pS} 6^{+} \mathrm{OPC}$ of an $h$ mgcs 1 mutant larva injected with both $p 53$ and ptena $\mathrm{MO}$. E, Graph showing the percentages of dorsal pS6 ${ }^{+} 0 \mathrm{PCs}(n=$ at least 23 larvae for each genotype and treatment; $p$ values were calculated using a Mann-Whitney test). $F-I$, Representative spinal cord images, viewed from a lateral position, obtained from $4 \mathrm{dpf} T g$ (olig2:EGFP) larvae labeled with antibodies to detect pErk (red) and GFP (green). $\boldsymbol{F}, \mathbf{G}$, Examples of pErk ${ }^{+} \mathrm{OPCs}$ in a wild-type larva injected with $p 53 \mathrm{M} 0$ and wild-type larva injected with both $p 53$ and ptena

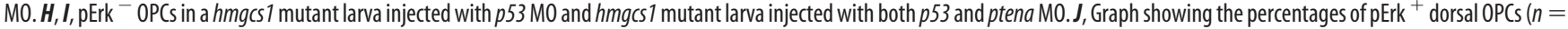
at least 20 larvae for each genotype and treatment; $p$ values were calculated using a Mann-Whitney test). Error bars represent the SEM. Scale bars, $10 \mu \mathrm{m}$.

mbpa and plpla (Fig. $4 D, H$ ), indicating that the activation of Akt signaling is sufficient to restore mbpa and plpla expression in cholesterol-deficient larvae. To test whether or not loss of ptena function promotes mbpa and plp1a expression by activating mTOR signaling, we treated larvae with rapamycin. Whereas wild-type and ptena $\mathrm{MO}$-injected wild-type larvae expressed mbpa and plpla after rapamycin treatment (Fig. 4I,J,M,N), rapamycin completely blocked the rescue of mbpa and plpla expression in hmgcsl mutant larvae that results from ptena loss of function (Fig. $4 K, L, O, P$ ). To confirm that activation of Akt signaling drives mbpa expression through mTOR activity and not through Erk signaling, we inhibited Erk activity using the MEK1/2 inhibitor U-0126 (Favata et al., 1998). Treatment of larvae with U-0126 reduced the proportion of $\mathrm{pERK}^{+}$dorsal OPCs to $0.63 \%$ compared with $9 \%$ in untreated larvae, indicating that the inhibitor effectively blocks MEK1/2 signaling. U-0126treated wild-type and ptena $\mathrm{MO}$-injected wild-type larvae expressed $m b p a$ and plpla robustly (Fig. $4 Q, R, U, V$ ). As expected, $h m g c s 1$ mutant larvae treated with U-0126 did not express $m b p a$ and plpla (Fig. $4 S, W$ ). In contrast to rapamycin, U-0126 treatment did not prevent the strong rescue of mbpa and plpla expression in hmgcsl mutant larvae injected with ptena $\mathrm{MO}$ (Fig. 4T,X). Therefore, Erk signaling is not required for $\mathrm{PIP}_{3} /$ Akt-mediated $m b p a$ and plp1a expression. Together with the above data, these results provide strong evidence that the PI3K/Akt/mTOR pathway transduces cholesterol-dependent signaling that promotes myelin gene expression.

\section{Cholesterol promotes axon ensheathment via Akt signaling in oligodendrocytes}

Our previous work showed that cholesterol is necessary for axon ensheathment by oligodendrocyte membrane (Mathews et al., 2014). Does cholesterol-dependent PI3K/Akt/mTOR signaling coordinately regulate myelin gene expression and axon wrapping? To address this question, we assessed myelin sheath formation using the transgenic reporter $\operatorname{Tg}(n k x 2.2 a: E G F P-C a a X)$, which expresses membrane-tethered EGFP in myelinating oligodendrocytes under the control of $n k x 2.2 a$ regulatory DNA (Kirby et al., 2006; Kucenas et al., 2008; Fig. 5A). Oligodendrocytes of wild-type larvae injected with ptena $\mathrm{MO}$ also wrapped axons (Fig. $5 B$ ), indicating that excess formation of $\mathrm{PIP}_{3}$ does not interfere with wrapping. Consistent with our previous results (Mathews et al., 2014), $n k \times 2.2 a^{+}$oligodendrocytes in $h m g c s 1$ mutant larvae extended membrane processes but did not wrap axons (Fig. 5C). By contrast, oligodendrocytes of hmgcs1 mutant larvae injected with ptena MO formed membrane sheaths (Fig. 5D). Thus, cholesterol-dependent axon ensheathment can be rescued by the elevation of $\mathrm{PIP}_{3}$ levels.

Does PI3K/Akt/mTOR signaling function within oligodendrocytes to promote axon ensheathment? To investigate this question, we injected newly fertilized eggs with plasmids encoding either reporter protein alone or a constitutively active form of Akt (Aoki et al., 1998) in oligodendrocyte lineage cells under control of sox10 regulatory DNA (Kirby et al., 2006). Consistent with our observations of oligodendrocytes marked by $n k x 2.2 a$ : EGFP-CaaX expression, cells expressing sox10:EGFP-CaaX in hmgcs1 mutant larvae did not wrap axons (Fig. 5E). By contrast, axon ensheathment was restored in sox $10^{+}$cells of hmgcs $1 \mathrm{mu}-$ tant larvae expressing activated Akt (Fig. $5 F$ ). The restored axon ensheathment resulted in an average sheath length of $17.8 \mu \mathrm{m}$ and a combined length of $118.1 \mu \mathrm{m}$. Thus, Akt activity within oligodendrocytes is sufficient to rescue the axon ensheathment defect that results from cholesterol deficiency.

Thus far, our data indicate that PI3K/Akt/mTOR pathway activity is necessary and sufficient to mediate cholesterol-dependent myelin gene expression and that Akt activity is sufficient 


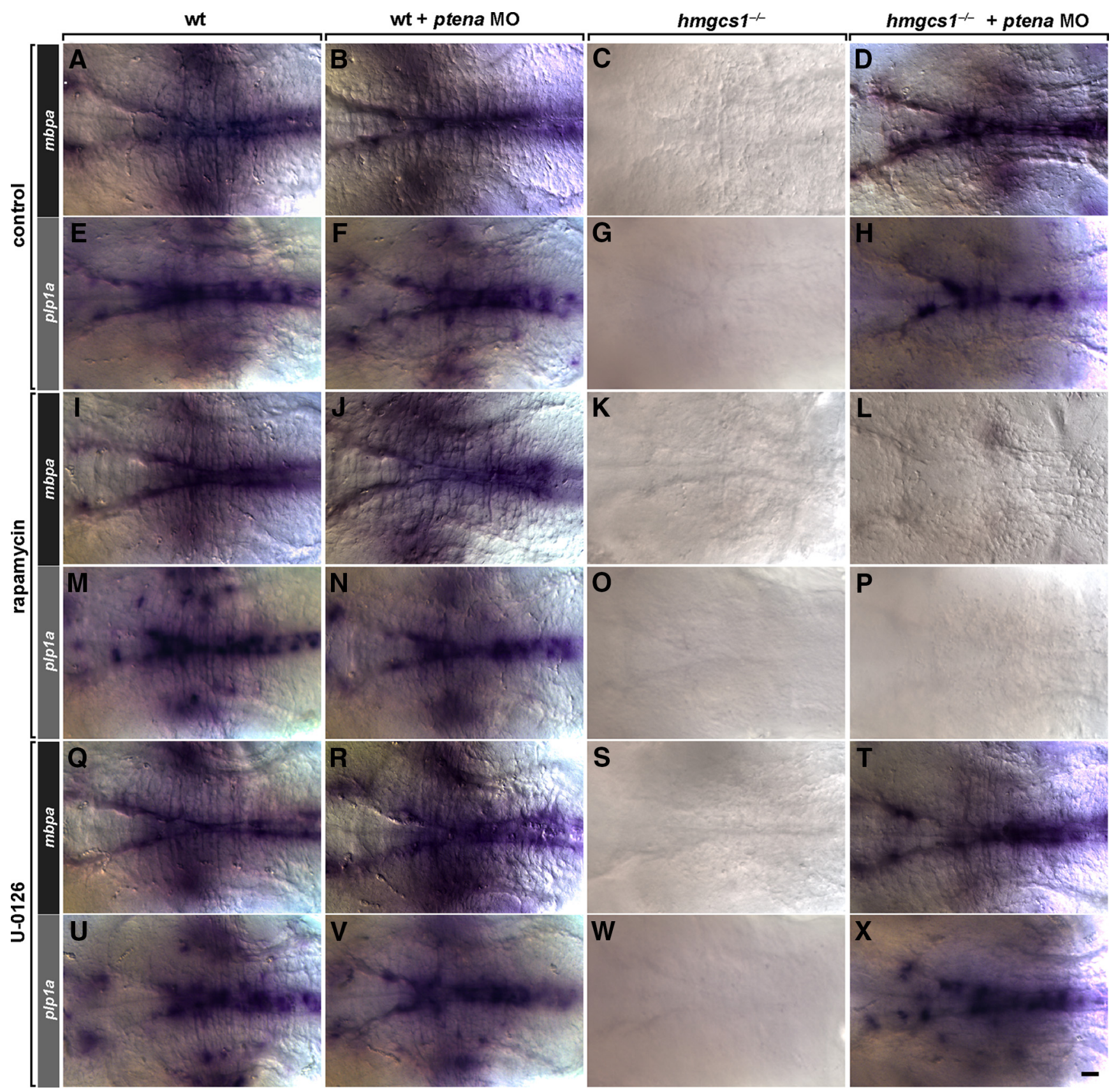

Figure 4. Activation of Akt signaling mediated through $m$ TOR is sufficient to restore myelin gene expression in $h m g c s 1$ mutant larvae. $A-X$, Representative maximum projections of $z$-stack optical sections of the hindbrain, viewed dorsally with anterior to the left, of 4 dpf larvae processed for mbpa and plp $1 a$ in situ RNA hybridization. $\boldsymbol{A}, \boldsymbol{B}, \boldsymbol{E}, \boldsymbol{F}$, Example of robust $m b p a$ and $p / p 1 a$ expression in a wild-type larva injected with $p 53 \mathrm{MO}(n=55$ of 55 and 76 of 76 larvae, respectively) and a wild-type larva injected with both $p 53$ and ptena $\mathrm{M} 0$ ( $n=154$ of 154 and 45 of 45 larvae, respectively). $\boldsymbol{C}, \mathbf{G}, h$ mgcs 1 mutant larva injected with $p 53 \mathrm{M0}$ expresses little mbpa $(n=40$ of 40 larvae $)$ and plp1a $(n=40$ of 40$)$. D, $\boldsymbol{H}$, mbpa and plp $1 a$ expression is restored in a $h m g c s 1$ mutant larva injected with both p53 and ptena $\mathrm{MO}$ (moderate to strong expression; $n=112$ of 140 and 54 of 57 larvae, respectively). $I, J, M, N$, Example of $m b p a$ and $p / p 1 a$ expression in a rapamycin-treated wild-type larva injected with p53 M0 ( $n=43$ of 43 and 86 of 86 larvae) and a rapamycin-treated wild-type larva injected with both p53 and ptena M0 ( $n=69$ of 69 and 41 of 41 larvae). $\boldsymbol{K}, \mathbf{L}, \mathbf{0}, \boldsymbol{P}$, Rapamycin-treated $h m g c s 1$ mutant larva injected with $p 53 \mathrm{MO}(n=82$ of 82 and 52 of 52 larvae), and rapamycin-treated hmgcs 1 mutant larva injected with both $p 53$ and ptena M0 express little mbpa and $p / p 1 a$ ( $n=52$ of 52 and 79 of 79 larvae). $\mathbf{Q}, \boldsymbol{R}, \boldsymbol{U}, \boldsymbol{V}$, Example of mbpa and plp $1 a$ expression in a U-0126-treated wild-type larva injected with $p 53 \mathrm{MO}$ ( $n=77$ of 77 and 69 of 69 larvae) and a U-0126-treated wild-type larvae with both $p 53$ and ptena MO ( $n=83$ of 83 and 42 of 42 larvae). S, W, U-0126-treated $h m g c s 1$ mutant larva injected with $p 53$ M0 expresses little $m b p a$ ( $n=$ 48 of 48 larvae) and $p / p 1 a$ ( $n=42$ of 42 larvae). $\boldsymbol{I}, X$, Example of robust $m b p a$ ( $n=65$ of 69 larvae) and $p / p 1 a$ ( $n=50$ of 56 larvae) expression in a hmgcs 1 mutant larva injected with both $p 53$ and ptena M0, and treated with U-0126. Scale bars, $20 \mu \mathrm{m}$.

to promote axon wrapping in the absence of cholesterol. Does cholesterol-dependent axon ensheathment also require mTOR activity? We previously showed that oligodendrocytes of mtor mutant larvae ensheath axons (Kearns et al., 2015), indicating that mTOR activity is not necessary for axon wrapping. Consistent with this observation, oligodendrocytes in wild-type larvae treated with rapamycin also wrapped axons (Fig. 6D). As expected, no wrapping was evident in hmgcsl mutant larvae treated with rapamycin (Fig. 6E). Notably, whereas rapamycin entirely blocked the rescue of $m b p a$ and plp1a expression in hmgcs 1 mutants that results from cholesterol or ptena MO injection (Figs. 2, 4), rapamycin-treated hmgcsl mutant larvae in- 

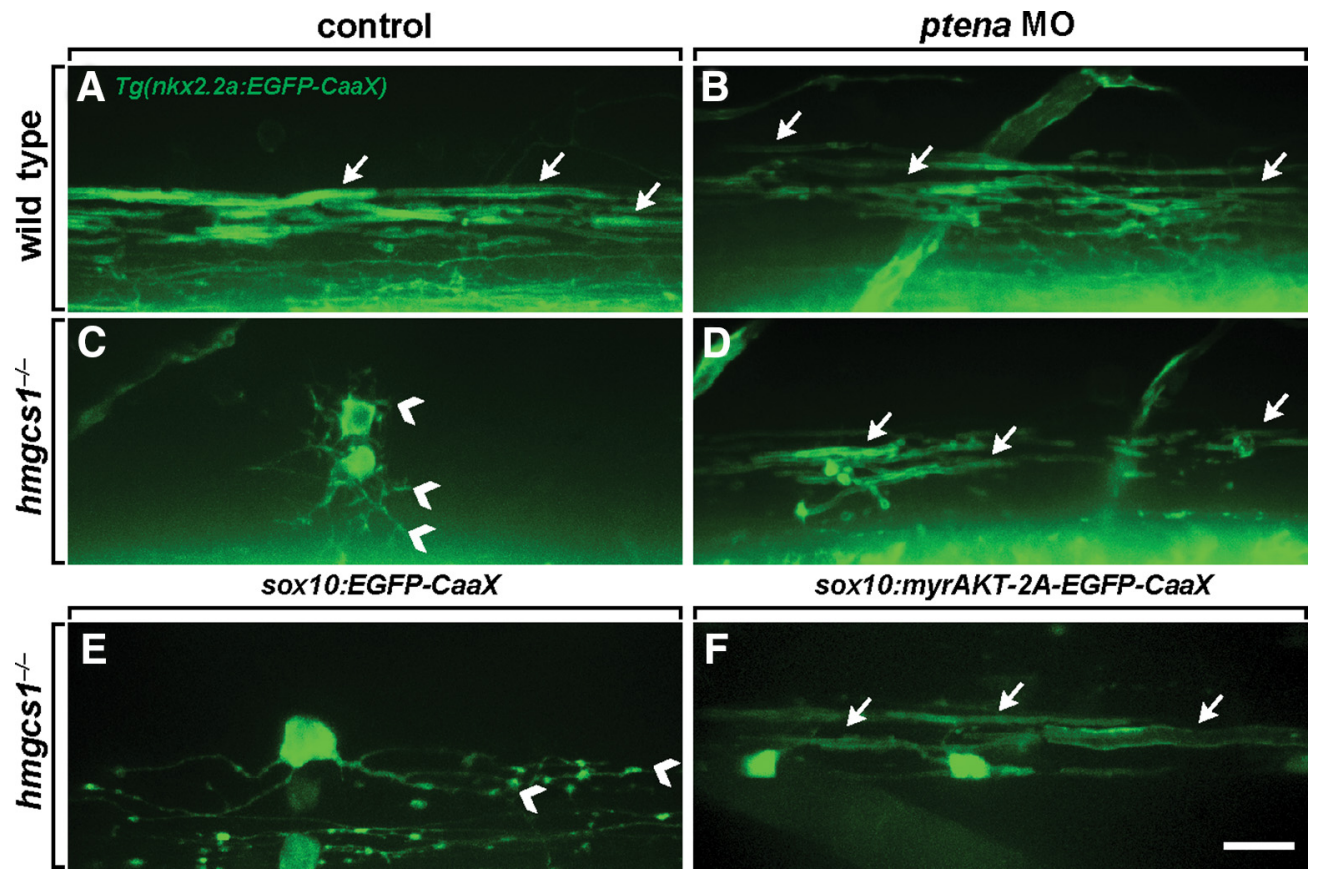

Figure 5. Akt activity is sufficient to promote axon wrapping in the absence of cholesterol. $\boldsymbol{A}-\boldsymbol{D}$, Representative maximum projections of $z$-stack optical sections, focused from a lateral position at the trunk spinal cord, of $4 \mathrm{dpf} T g(n k x 2.2 a$ :EGFP-CaaX) larvae. $A, B$, Several myelinating oligodendrocytes with visible myelin sheaths (arrows) are evident in a control wild-type larva injected with $p 53 \mathrm{M0}(n=91$ larvae) and in a wild-type larva injected with both $p 53$ and ptena M0 ( $n=75$ larvae). C, Numerous processes (arrowheads) extending from an oligodendrocyte are evident, but myelin sheaths are not formed in $h m g c s 1$ larvae injected with $p 53 \mathrm{MO}$ ( $n=204$ cells). $\boldsymbol{D}$, Myelin sheaths are evident in an $h m g c s 1$ mutant larva injected with both $p 53$ and ptena $\mathrm{MO}(n=68$ cells). $\boldsymbol{E}, \boldsymbol{F}$, Representative maximum projections of $z$-stack optical sections, focused from a lateral position at the trunk spinal cord, of $4 \mathrm{dpf}$ larvae injected with either sox10:EGFP-CaaX or sox10:myrAKT-2A-EGFP-CaaX. E, Numerous processes extending from an oligodendrocyte are evident in the $h m g c s 1$ mutant larva injected with sox10:EGFP-CaaX plasmid ( $n=72$ cells). $\boldsymbol{F}$, Myelin sheaths are evident in an hmgcs 1 mutant larva injected with sox10:myrAKT-2A-EGFP-CaaX ( $n=45$ cells). Scale bars, $10 \mu \mathrm{m}$.

jected with cholesterol (Fig. 6F) or ptena MO (Fig. 6O) formed membrane sheaths. Similarly, treatment with U-0126 to block Erk activity did not prevent axon wrapping in wild-type larvae (Fig. 6G), hmgcs1 mutant larvae injected with cholesterol (Fig. $6 I$ ), or hmgcs1 mutant larvae injected with ptena MO (Fig. 6R). Altogether, these data indicate that cholesterol and PI3K/Akt signaling promote axon wrapping independently of mTOR or Erk functions.

\section{mTOR signaling regulates myelin sheath length}

Our results show that rapamycin blocks cholesterol-dependent myelin gene expression, but not cholesterol-dependent axon ensheathment. These observations raise the possibility that mTOR promotes cholesterol-dependent myelin sheath growth separately from axon ensheathment. Consistent with this possibility, rapamycin treatment reduced the average and total length of oligodendrocyte sheaths in hmgcs 1 mutant larvae in which axon ensheathment was rescued by the injection of cholesterol or ptena $\mathrm{MO}$ (Fig. $6 S, T, V, W$ ). Average sheath length and total length also were slightly reduced by treatment with the Erk inhibitor U-0126 (Fig. $6 S, T, V, W)$. By contrast, the number of sheaths per oligodendrocyte did not change with either rapamycin or U-0126 treatment (Fig. 6U,X).

To further investigate the regulation of sheath length, we used larvae having the transgenic combination $\mathrm{Tg}$ (sox10: GAL4-VP16, cmlc2:Cerulean); $T g(4 x n r U A S: E G F P-C a a X, c m l c 2:$ EGFP) (Mathews et al., 2014), which express membrane-tethered EGFP in a subset of oligodendrocytes. Rapamycin, but not U-0126, reduced average and total sheath length relative to those in untreated control larvae (Fig. $7 A-C, J, K$ ), indicating that in wild-type larvae mTOR, but not Erk, signaling drives sheath extension. The average and total sheath lengths were increased in ptena MO-injected larvae relative to p53 MO-injected control larvae, but this effect was reversed both by rapamycin and U-0126 treatment (Fig. $7 D-K)$. The inhibition of ptena and treatment with either rapamycin or U-0126 did not change the number of sheaths produced per oligodendrocyte (Fig. $7 L$ ). Thus, both mTOR and Erk signaling contribute to the excessive sheath length that results from ptena loss of function.

\section{Discussion}

Myelin is remarkably rich in cholesterol. The human brain contains $\sim 25 \%$ of all cholesterol in the body (Dietschy and Turley, 2004) and myelin may hold as much as $80 \%$ of brain cholesterol (Muse et al., 2001; Dietschy and Turley, 2004). Cholesterol does not cross the blood-brain barrier, consequently, neural cells must produce the large amounts of cholesterol found in myelin. Why is cholesterol so highly enriched in myelin? One possibility is that cholesterol interacts with myelin proteins (Simons et al., 2000; Krämer-Albers et al., 2006; Saher et al., 2009) and could thereby contribute to myelin assembly and the tight compaction of myelin membrane that make it a good electrical insulator. Additionally, the cholesterol content of a membrane influences its fluidity (Brûlet and McConnell, 1976; Cooper, 1978; Xu and London, 2000). Myelin membrane appears to spread like a liquid droplet as it grows on axons (Nawaz et al., 2015). Consequently, cholesterol might influence myelin membrane spreading. Curiously, cholesterol also is necessary for the expression of genes that encode myelin proteins. For example, oligodendrocyte-specific mutation of squalene synthase, an enzyme required for cholesterol synthesis, in mice caused hypomyelination associated with reduced levels of myelin gene transcripts (Saher et al., 2005). Likewise, pharmacological inhibition of cholesterol synthesis in vitro using statins reduced the amount of myelin gene transcripts 

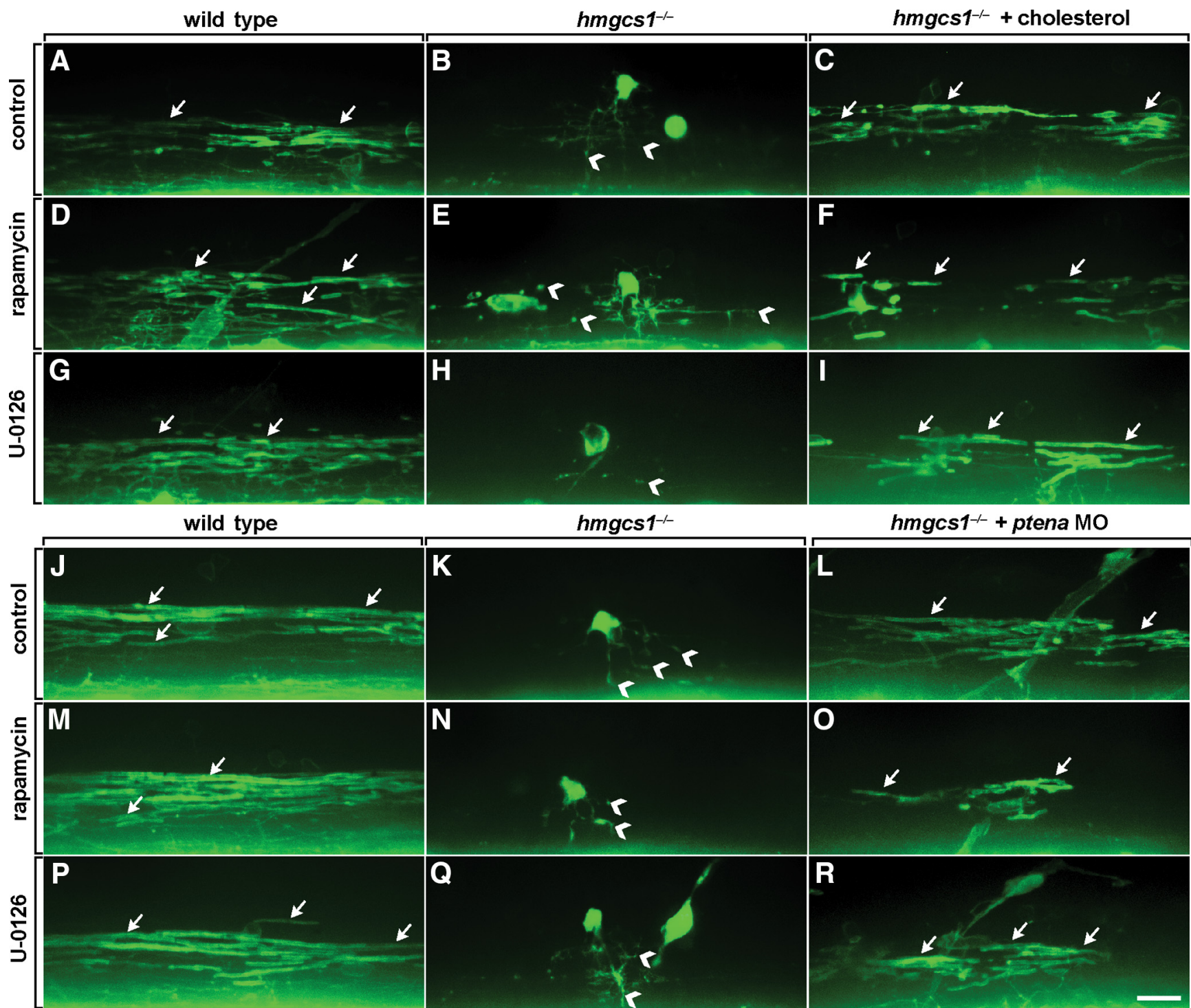

hmgcs1 ${ }^{-/}+$ptena MO
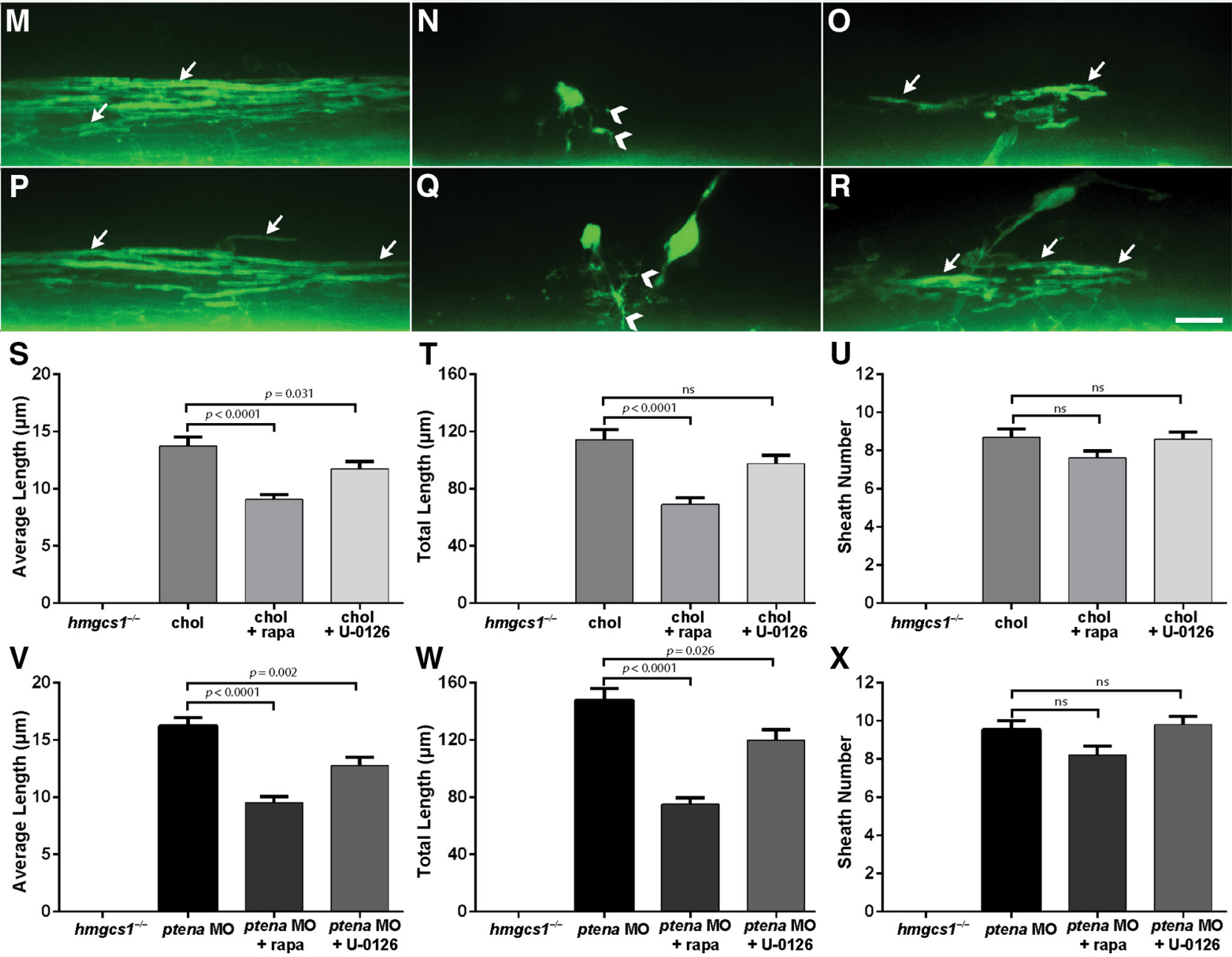

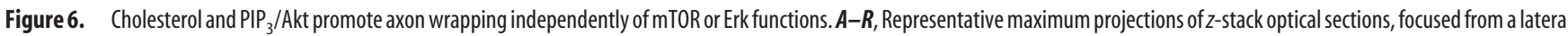
position at the trunk spinal cord, of $4 \mathrm{dpf} \operatorname{Tg}(n k \times 2.2 a$ :EGFP-CaaX) larvae. $\boldsymbol{A}$, Several myelinating oligodendrocytes with visible myelin sheaths (arrows) are evident (Figure legend continues.) 


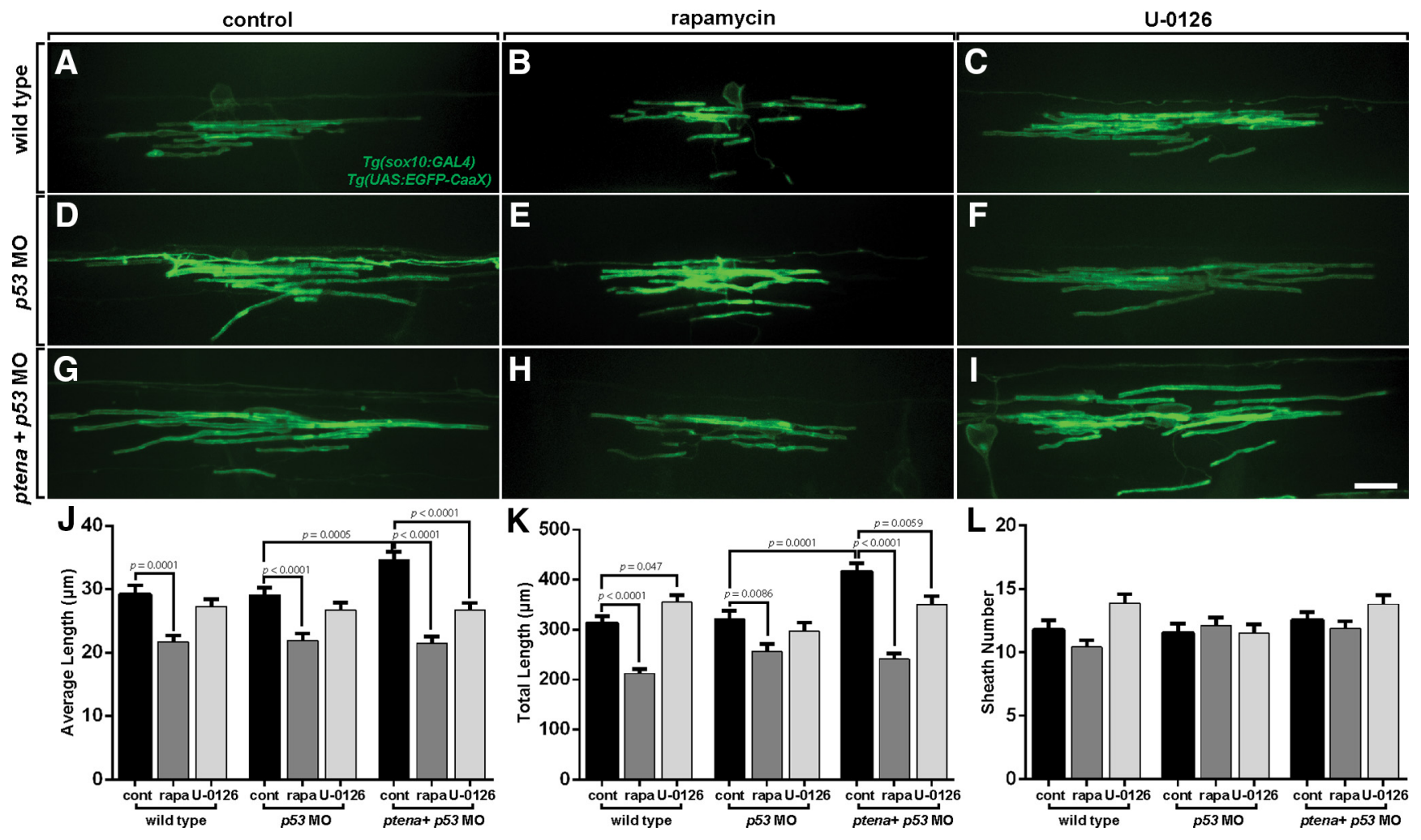

Figure 7. Both $m T O R$ and Erk signaling contribute to the excessive sheath length that results from ptena loss of function. $A-I$, Representative maximum projections of $z$-stack optical sections, focused from a lateral position at the trunk spinal cord, of $4 \mathrm{dpf}$ Tg(sox10:GAL4-VP16, cmlc2:Cerulean);Tg(4xnrUAS:EGFP-CaaX, cmlc2:EGFP) larvae. A, Example of a single oligodendrocyte with numerous myelin sheaths (arrows) in a control-treated larva ( $n=38$ cells). $\boldsymbol{B}$, Noticeably shorter sheaths are evident in a rapamycin-treated larva $(n=45$ cells). $\boldsymbol{C}$, Example of a single oligodendrocyte with numerous myelin sheaths in a U-0126-treated larva ( $n=43$ cells). $\boldsymbol{D}$, Example of a single oligodendrocyte in a control-treated $p 53 \mathrm{M} 0$ injected larva $(n=30$ cells). $\boldsymbol{E}$, Noticeably shorter sheaths are evident in a rapamycin-treated larva injected with $p 53 \mathrm{MO}(n=27$ cells). $\boldsymbol{F}$, Example of a single oligodendrocyte in a U-0126-treated larva injected with $p 53 \mathrm{MO}$ ( $n=23$ cells). G, Markedly longer sheaths are evident in a $p 53$ and ptena M0-injected larva ( $n=44$ cells). $\boldsymbol{H}, \boldsymbol{I}$, Rapamycin-treated larva injected with both $p 53$ and ptena M0 $(n=47$ cells), and U-0126-treated larva injected with both $p 53$ and ptena MO ( $n=38$ cells) display noticeably shorter myelin sheaths. $J-L$, Graphs showing the average sheath length, average total sheath length, and sheath number per oligodendrocyte ( $n=$ at least 17 larvae for each treatment; $p$ values were calculated using a Mann-Whitney test). Error bars represent the SEM. Scale bars, $10 \mu \mathrm{m}$.

and caused retraction of oligodendrocyte processes (Miron et al., 2007; Smolders et al., 2010). Consistent with these results, our own work showed that cholesterol-deficient zebrafish larvae expressed myelin gene mRNAs at abnormally low levels (Mathews

(Figure legend continued.) in a control wild-type larva ( $n=105$ larvae). $\boldsymbol{B}$, Numerous processes (arrowheads) extending from an oligodendrocyte are evident, but myelin sheaths are not formed in $h m g$ cs 1 larvae ( $n=125$ cells). C, Myelin sheaths are evident in a cholesterol-injected hmgcs1 mutant larva ( $n=37$ cells). $\boldsymbol{D}$, Myelin sheaths are evident in a rapamycin-treated wild-type larva ( $n=94$ larvae). $E$, Myelin sheaths are not formed in $h m g c s 1$ larvae treated with rapamycin ( $n=111$ cells). $\boldsymbol{F}$, Myelin sheaths are evident after rapamycin treatment in a cholesterol-injected hmgcs 1 mutant larva ( $n=36$ cells). $\mathbf{G}$, Myelin sheaths are evident in a U-0126-treated wild-type larva ( $n=74$ larvae). $\boldsymbol{H}$, Myelin sheaths are not formed in $h m g$ cs 1 larvae treated with U-0126 ( $n=77$ cells). I, Myelin sheaths are evident after U-0126 treatment in a cholesterol-injected $h m g c s 1$ mutant larva ( $n=52$ cells). $J, M, P$, Myelin sheaths are evident in wild-type larvae injected with $p 53 \mathrm{MO}$, and treated with DMSO ( $n=91$ larvae), rapamycin ( $n=74$ larvae), and U-0126 ( $n=83$ larvae). $\boldsymbol{K}, \mathbf{N}, \mathbf{Q}$, Myelin sheaths are not formed in $h m g$ cs 1 larvae injected with $p 53 \mathrm{MO}$, and treated with DMSO ( $n=204$ cells), rapamycin ( $n=246$ cells), and U-0126 ( $n=165$ cells). $\boldsymbol{L}, \mathbf{O}, \boldsymbol{R}$, Myelin sheaths are evident in $p 53$ and ptena M0-injected hmgcs 1 mutant larvae treated with DMSO ( $n=68$ cells), rapamycin ( $n=41$ cells), and U-0126 ( $n=48$ cells). S-U, Graphs showing the average sheath length, average total sheath length, and sheath number per oligodendrocyte after cholesterol injection $(n=$ at least 20 larvae for each treatment; $p$ values were calculated using a Mann-Whitney test). $\boldsymbol{V}-\boldsymbol{X}$, Graphs showing the average sheath length, average total sheath length, and sheath number per oligodendrocyte after ptena M0 injection ( $n=$ at least 20 larvae for each treatment; $p$ values were calculated using a Mann-Whitney test). Error bars represent the SEM. Scale bars, $10 \mu \mathrm{m}$. et al., 2014). The molecular mechanisms that connect cholesterol to myelin gene expression are not known.

Because cholesterol can organize membrane microdomains that function as platforms for signaling molecules (Hoessli et al., 2000; Simons and Toomre, 2000), we hypothesized that cholesterol enables signal transduction that promotes myelin gene expression. We focused on the PI3K/Akt/ mTOR signaling pathway because it promotes cholesterol biosynthetic pathway gene expression through activation of the SREBP (sterol regulatory element binding protein) transcription factors (Porstmann et al., 2008; Düvel et al., 2010; Li et al., 2010), and it is a major driver of CNS myelin protein expression. Inhibition of mTOR activity in vitro using the pharmacological inhibitor rapamycin and conditional mutation of $m T O R$ in mice substantially reduced myelin gene transcript and myelin protein levels (Tyler et al., 2009; Wahl et al., 2014). Similarly, mtor mutant zebrafish larvae were deficient for the expression of myelin and cholesterol synthesis pathway genes (Kearns et al., 2015). Conversely, conditional inactivation of PTEN, a phosphatase that negatively regulates $\mathrm{PIP}_{3}$ accumulation and Akt activation, and oligodendrocytespecific expression of constitutively active Akt caused hypermyelination phenotypes (Flores et al., 2008; Goebbels et al., 2010; Harrington et al., 2010). The PI3K/Akt/mTOR pathway can be stimulated by numerous extracellular cues, including receptor tyrosine kinases, but the particular signals that acti- 
vate $\mathrm{PI} 3 \mathrm{~K} / \mathrm{Akt} / \mathrm{mTOR}$ functions to promote myelination are not known.

In this article, we presented several lines of evidence that the requirement for cholesterol in myelination reflects, in part, cholesterol-dependent PI3K/Akt/mTOR signaling. First, using a molecular readout of mTOR kinase activity, we found that hmgcs1 mutant zebrafish larvae had substantially fewer mTORactive oligodendrocyte lineage cells. Importantly, mTOR activity could be restored by the injection of soluble cholesterol, indicating that mTOR activity requires cholesterol, and not protein prenylation, which also depends on Hmgcs1 function. Second, we followed up our previous demonstration that cholesterol injection rescues both mbpa and plpla RNA expression in hmgcs 1 mutant larvae to show here that rescue requires mTOR activity. Third, we found that inactivation of PTEN restored mTOR signaling, and mbpa and plp1a RNA expression in hmgcsl mutant larvae, and, like cholesterol injection, that RNA expression rescue required mTOR function.

Whereas hmgcs1 mutant zebrafish larvae express myelin gene mRNAs at $\sim 20-40 \%$ of normal levels (Mathews et al., 2014), loss of mTOR function in mice or zebrafish has more modest effects on myelin gene transcript levels (Wahl et al., 2014; Kearns et al., 2015). This raises the possibility that other myelin-promoting signaling pathways also require cholesterol. One possibility is the MEK/Erk pathway because oligodendrocyte-specific mutation of Erk1/Erk2 in mice resulted in a failure to upregulate the transcription of major myelin genes (Ishii et al., 2012) and oligodendrocyte-specific activation of Erk1/Erk2 significantly increased myelin thickness (Ishii et al., 2013). However, our own studies did not uncover strong evidence of cholesterol-dependent MEK/Erk signaling in zebrafish myelination. For example, although hmgcs1 mutant larvae had fewer Erk-active oligodendrocyte lineage cells, Erk signaling was not rescued by cholesterol injection. One interpretation of this result is that Erk signaling in oligodendrocyte lineage cells requires protein prenylation, which results from a post-translation modification pathway downstream of Hmgcs1 (Ahearn et al., 2012). Consistent with this possibility, Ras, which activates the MEK/Erk pathway, is prenylated. Consequently, reduced MEK/Erk signaling in hmgcs 1 mutant larvae might result from reduced protein prenylation and not cholesterol deficiency. Additionally, PTEN inactivation did not restore Erk signaling activity in oligodendrocytes of $h m g c s 1$ mutant larvae, nor did the ability of PTEN inactivation to rescue mbpa RNA expression in $h m g c s 1$ mutant larvae require Erk signaling. We therefore conclude that PI3K/Akt/mTOR signaling, but not MEK/Erk signaling, contributes significantly to the cholesterol-dependent myelination program.

Our current work also provides insights into the mechanisms of axon wrapping. Recent publications have described how myelin membrane wraps and lengthens along axons (Snaidero et al., 2014), and how changes in the actin cytoskeleton help to move the leading edge of the membrane (Nawaz et al., 2015; Zuchero et al., 2015). However, little is yet known about signaling mechanisms that help coordinate myelin membrane growth and axon wrapping. We previously showed that cholesterol is required for axon ensheathment (Mathews et al., 2014). In the current work, we found that PTEN inactivation could rescue at least some degree of ensheathment in the absence of cholesterol, which is consistent with the observation that PTEN inactivation promotes growth at the leading edge of myelin membrane (Snaidero et al., 2014). Inhibiting mTOR signaling with rapamycin reduced the lengths of sheaths formed following PTEN inactivation, which is similar to our previous observations showing that mTOR activity modulates sheath length (Kearns et al., 2015), but it did not pre- vent ensheathment. This result suggests that elevation of $\mathrm{PIP}_{3}$ levels can promote ensheathment independently of mTOR activity. Accordingly, we found that oligodendrocyte-specific expression of a constitutively active form of Akt rescued axon wrapping in $h m g c s 1$ mutant larvae. Together, our data indicate that mTOR activity mediates cholesterol-dependent myelin gene expression and sheath length extension, but that Akt independently promotes axon ensheathment.

Myelination requires coordination of mechanisms that promote the production of myelin proteins, enabling myelin growth, with those that regulate actin cytoskeletal dynamics to facilitate axon wrapping. Cholesterol-rich membrane microdomains can anchor actin filaments (Taguchi et al., 2005), and our work indicates that cholesterol is required for signaling that promotes both myelin growth and wrapping. Thus, the enrichment of cholesterol in nascent myelin membrane may provide a hub for cytoskeletal elements and signaling molecules, thereby helping to synchronize myelin growth and wrapping.

\section{References}

Ahearn IM, Haigis K, Bar-Sagi D, Philips MR (2012) Regulating the regulator: post-translational modification of RAS. Nat Rev Mol Cell Biol 13: 39-51. CrossRef Medline

Aoki M, Batista O, Bellacosa A, Tsichlis P, Vogt PK (1998) The akt kinase: molecular determinants of oncogenicity. Proc Natl Acad Sci U S A 95: 14950-14955. CrossRef Medline

Bercury KK, Dai J, Sachs HH, Ahrendsen JT, Wood TL, Macklin WB (2014) Conditional ablation of raptor or rictor has differential impact on oligodendrocyte differentiation and CNS myelination. J Neurosci 34:4466-4480. CrossRef Medline

Brösamle C, Halpern ME (2002) Characterization of myelination in the developing zebrafish. Glia 39:47-57. CrossRef Medline

Brown EJ, Albers MW, Shin TB, Ichikawa K, Keith CT, Lane WS, Schreiber SL (1994) A mammalian protein targeted by G1-arresting rapamycinreceptor complex. Nature 369:756-758. CrossRef Medline

Brûlet P, McConnell HM (1976) Lateral hapten mobility and immunochemistry of model membranes. Proc Natl Acad Sci U S A 73:2977-2981. CrossRef Medline

Cooper RA (1978) Influence of increased membrane cholesterol on membrane fluidity and cell function in human red blood cells. J Supramol Struct 8:413-430. CrossRef Medline

Croushore JA, Blasiole B, Riddle RC, Thisse C, Thisse B, Canfield VA, Robertson GP, Cheng KC, Levenson R (2005) ptena and ptenb genes play distinct roles in zebrafish embryogenesis. Dev Dyn 234:911-921. CrossRef Medline

Decker L, ffrench-Constant C (2004) Lipid rafts and integrin activation regulate oligodendrocyte survival. J Neurosci 24:3816-3825. CrossRef Medline

Dietschy JM, Turley SD (2004) Thematic review series: brain Lipids. Cholesterol metabolism in the central nervous system during early development and in the mature animal. J Lipid Res 45:1375-1397. CrossRef Medline

Düvel K, Yecies JL, Menon S, Raman P, Lipovsky AI, Souza AL, Triantafellow E, Ma Q, Gorski R, Cleaver S, Vander Heiden MG, MacKeigan JP, Finan PM, Clish CB, Murphy LO, Manning BD (2010) Activation of a metabolic gene regulatory network downstream of mTOR complex 1. Mol Cell 39:171-183. CrossRef Medline

Favata MF, Horiuchi KY, Manos EJ, Daulerio AJ, Stradley DA, Feeser WS, Van Dyk DE, Pitts WJ, Earl RA, Hobbs F, Copeland RA, Magolda RL, Scherle PA, Trzaskos JM (1998) Identification of a novel inhibitor of mitogen-activated protein kinase kinase. J Biol Chem 273:18623-18632. CrossRef Medline

Flores AI, Narayanan SP, Morse EN, Shick HE, Yin X, Kidd G, Avila RL, Kirschner DA, Macklin WB (2008) Constitutively active Akt induces enhanced myelination in the CNS. J Neurosci 28:7174-7183. CrossRef Medline

Franke TF, Kaplan DR, Cantley LC, Toker A (1997) Direct regulation of the Akt proto-oncogene product by phosphatidylinositol-3,4-bisphosphate. Science 275:665-668. CrossRef Medline

Fyffe-Maricich SL, Karlo JC, Landreth GE, Miller RH (2011) The ERK2 mitogen-activated protein kinase regulates the timing of oligodendrocyte differentiation. J Neurosci 31:843-850. CrossRef Medline 
Fyffe-Maricich SL, Schott A, Karl M, Krasno J, Miller RH (2013) Signaling through ERK1/2 controls myelin thickness during myelin repair in the adult central nervous system. J Neurosci 33:18402-18408. CrossRef Medline

Goebbels S, Oltrogge JH, Kemper R, Heilmann I, Bormuth I, Wolfer S, Wichert SP, Möbius W, Liu X, Lappe-Siefke C, Rossner MJ, Groszer M, Suter U, Frahm J, Boretius S, Nave KA (2010) Elevated phosphatidylinositol 3,4,5-trisphosphate in glia triggers cell-autonomous membrane wrapping and myelination. J Neurosci 30:8953-8964. CrossRef Medline

Guardiola-Diaz HM, Ishii A, Bansal R (2012) Erk1/2 MAPK and mTOR signaling sequentially regulates progression through distinct stages of oligodendrocyte differentiation. Glia 60:476-486. CrossRef Medline

Harrington EP, Zhao C, Fancy SP, Kaing S, Franklin RJ, Rowitch DH (2010) Oligodendrocyte PTEN is required for myelin and axonal integrity, not remyelination. Ann Neurol 68:703-716. CrossRef Medline

Hauptmann G, Gerster T (2000) Multicolor whole-mount in situ hybridization. Methods Mol Biol 137:139-148. Medline

Heitman J, Movva NR, Hall MN (1991) Targets for cell cycle arrest by the immunosuppressant rapamycin in yeast. Science 253:905-909. CrossRef Medline

Hoessli DC, Ilangumaran S, Soltermann A, Robinson PJ, Borisch B, NasirUd-Din (2000) Signaling through sphingolipid microdomains of the plasma membrane: the concept of signaling platform. Glycoconj J 17: 191-197. CrossRef Medline

Inoki K, Li Y, Zhu T, Wu J, Guan KL (2002) TSC2 is phosphorylated and inhibited by Akt and suppresses mTOR signalling. Nat Cell Biol 4: 648-657. CrossRef Medline

Ishii A, Fyffe-Maricich SL, Furusho M, Miller RH, Bansal R (2012) ERK1/ ERK2 MAPK signaling is required to increase myelin thickness independent of oligodendrocyte differentiation and initiation of myelination. J Neurosci 32:8855-8864. CrossRef Medline

Ishii A, Furusho M, Bansal R (2013) Sustained activation of ERK1/2 MAPK in oligodendrocytes and schwann cells enhances myelin growth and stimulates oligodendrocyte progenitor expansion. J Neurosci 33: 175-186. CrossRef Medline

Kearns CA, Ravanelli AM, Cooper K, Appel B (2015) Fbxw7 limits myelination by inhibiting mTOR signaling. J Neurosci 35:14861-14871. CrossRef Medline

Kimmel CB, Ballard WW, Kimmel SR, Ullmann B, Schilling TF (1995) Stages of embryonic development of the zebrafish. Dev Dyn 203:253-310. CrossRef Medline

Kirby BB, Takada N, Latimer AJ, Shin J, Carney TJ, Kelsh RN, Appel B (2006) In vivo time-lapse imaging shows dynamic oligodendrocyte progenitor behavior during zebrafish development. Nat Neurosci 9:1506-1511. CrossRef Medline

Krämer-Albers EM, Gehrig-Burger K, Thiele C, Trotter J, Nave KA (2006) Perturbed interactions of mutant proteolipid protein/DM20 with cholesterol and lipid rafts in oligodendroglia: implications for dysmyelination in spastic paraplegia. J Neurosci 26:11743-11752. CrossRef Medline

Kucenas S, Snell H, Appel B (2008) nkx2.2a promotes specification and differentiation of a myelinating subset of oligodendrocyte lineage cells in zebrafish. Neuron Glia Biol 4:71-81. CrossRef Medline

Kwan KM, Fujimoto E, Grabher C, Mangum BD, Hardy ME, Campbell DS, Parant JM, Yost HJ, Kanki JP, Chien CB (2007) The Tol2kit: a multisite gateway-based construction kit for Tol2 transposon transgenesis constructs. Dev Dyn 236:3088-3099. CrossRef Medline

Laplante M, Sabatini DM (2009) mTOR signaling at a glance. J Cell Sci 122:3589-3594. CrossRef Medline

Li S, Brown MS, Goldstein JL (2010) Bifurcation of insulin signaling pathway in rat liver: $\mathrm{mTORC1}$ required for stimulation of lipogenesis, but not inhibition of gluconeogenesis. Proc Natl Acad Sci U S A 107:3441-3446. CrossRef Medline

Manning BD, Tee AR, Logsdon MN, Blenis J, Cantley LC (2002) Identification of the tuberous sclerosis complex-2 tumor suppressor gene product tuberin as a target of the phosphoinositide 3-kinase/Akt pathway. Mol Cell 10:151-162. CrossRef Medline

Mathews ES, Mawdsley DJ, Walker M, Hines JH, Pozzoli M, Appel B (2014) Mutation of 3-hydroxy-3-methylglutaryl CoA synthase I reveals requirements for isoprenoid and cholesterol synthesis in oligodendrocyte migration arrest, axon wrapping, and myelin gene expression. J Neurosci 34: 3402-3412. CrossRef Medline

McKay MM, Morrison DK (2007) Integrating signals from RTKs to ERK/ MAPK. Oncogene 26:3113-3121. CrossRef Medline
Miron VE, Rajasekharan S, Jarjour AA, Zamvil SS, Kennedy TE, Antel JP (2007) Simvastatin regulates oligodendroglial process dynamics and survival. Glia 55:130-143. CrossRef Medline

Morand OH, Aebi JD, Dehmlow H, Ji YH, Gains N, Lengsfeld H, Himber J (1997) Ro 48-8.071, a new 2,3-oxidosqualene:lanosterol cyclase inhibitor lowering plasma cholesterol in hamsters, squirrel monkeys, and minipigs: comparison to simvastatin. J Lipid Res 38:373-390. Medline

Morell P, Jurevics H (1996) Origin of cholesterol in myelin. Neurochem Res 21:463-470. CrossRef Medline

Morell P, Quarles R (1999) Myelin formation, structure and biochemistry. In Basic neurochemistry (Siegel G, Agranoff B, Alber R, Risher S, Uhler M, eds), pp 70-93. New York: Raven.

Muse ED, Jurevics H, Toews AD, Matsushima GK, Morell P (2001) Parameters related to lipid metabolism as markers of myelination in mouse brain. J Neurochem 76:77-86. CrossRef Medline

Nagy P, Vereb G, Sebestyén Z, Horváth G, Lockett SJ, Damjanovich S, Park JW, Jovin TM, Szöllosi J (2002) Lipid rafts and the local density of ErbB proteins influence the biological role of homo- and heteroassociations of ErbB2. J Cell Sci 115:4251-4262. CrossRef Medline

Narayanan SP, Flores AI, Wang F, Macklin WB (2009) Akt signals through the mammalian target of rapamycin pathway to regulate CNS myelination. J Neurosci 29:6860-6870. CrossRef Medline

Nawaz S, Sánchez P, Schmitt S, Snaidero N, Mitkovski M, Velte C, Brückner BR, Alexopoulos I, Czopka T, Jung SY, Rhee JS, Janshoff A, Witke W, Schaap IA, Lyons DA, Simons M (2015) Actin filament turnover drives leading edge growth during myelin sheath formation in the central nervous system. Dev Cell 34:139-151. CrossRef Medline

Pike LJ (2006) Rafts defined: a report on the Keystone symposium on lipid rafts and cell function. J Lipid Res 47:1597-1598. CrossRef Medline

Porstmann T, Santos CR, Griffiths B, Cully M, Wu M, Leevers S, Griffiths JR, Chung YL, Schulze A (2008) SREBP activity is regulated by mTORC1 and contributes to Akt-dependent cell growth. Cell Metab 8:224-236. CrossRef Medline

Robu ME, Larson JD, Nasevicius A, Beiraghi S, Brenner C, Farber SA, Ekker SC (2007) P53 activation by knockdown technologies. PLoS Genet 3:e78. CrossRef Medline

Sabatini DM, Erdjument-Bromage H, Lui M, Tempst P, Snyder SH (1994) RAFT1: a mammalian protein that binds to FKBP12 in a rapamycin-dependent fashion and is homologous to yeast TORs. Cell 78:35-43. CrossRef Medline

Sabers CJ, Martin MM, Brunn GJ, Williams JM, Dumont FJ, Wiederrecht G, Abraham RT (1995) Isolation of a protein target of the FKBP12-rapamycin complex in mammalian cells. J Biol Chem 270:815-822. CrossRef Medline

Saher G, Brügger B, Lappe-Siefke C, Möbius W, Tozawa R, Wehr MC, Wieland F, Ishibashi S, Nave KA (2005) High cholesterol level is essential for myelin membrane growth. Nat Neurosci 8:468-475. CrossRef Medline

Saher G, Quintes S, Möbius W, Wehr MC, Krämer-Albers E-M, Brügger B, Nave KA (2009) Cholesterol regulates the endoplasmic reticulum exit of the major membrane protein $\mathrm{P} 0$ required for peripheral myelin compaction. J Neurosci 29:6094-6104. CrossRef Medline

Saher G, Quintes S, Nave KA (2011) Cholesterol: a novel regulatory role in myelin formation. Neuroscientist 17:79-93. CrossRef Medline

Sherman DL, Krols M, Wu LM, Grove M, Nave KA, Gangloff YG, Brophy PJ (2012) Arrest of myelination and reduced axon growth when Schwann cells lack mTOR. J Neurosci 32:1817-1825. CrossRef Medline

Shin J, Park HC, Topczewska JM, Mawdsley DJ, Appel B (2003) Neural cell fate analysis in zebrafish using olig2 BAC transgenics. Methods Cell Sci 25:7-14. CrossRef Medline

Simons K, Toomre D (2000) Lipid rafts and signal transduction. Nat Rev Mol Cell Biol 1:31-39. CrossRef Medline

Simons M, Krämer EM, Thiele C, Stoffel W, Trotter J (2000) Assembly of myelin by association of proteolipid protein with cholesterol- and galactosylceramide-rich membrane domains. J Cell Biol 151:143-154. CrossRef Medline

Smolders I, Smets I, Maier O, vandeVen M, Steels P, Ameloot M (2010) Simvastatin interferes with process outgrowth and branching of oligodendrocytes. J Neurosci Res 88:3361-3375. CrossRef Medline

Snaidero N, Möbius W, Czopka T, Hekking LH, Mathisen C, Verkleij D, Goebbels S, Edgar J, Merkler D, Lyons DA, Nave KA, Simons M (2014) Myelin membrane wrapping of CNS axons by PI(3,4,5)P3dependent polarized growth at the inner tongue. Cell 156:277-290. CrossRef Medline 
Stokoe D, Stephens LR, Copeland T, Gaffney PR, Reese CB, Painter GF, Holmes AB, McCormick F, Hawkins PT (1997) Dual role of phosphatidylinositol-3,4,5-trisphosphate in the activation of protein kinase $B$. Science 277:567-570. CrossRef Medline

Taguchi K, Yoshinaka K, Yoshino K, Yonezawa K, Maekawa S (2005) Biochemical and morphologic evidence of the interaction of oligodendrocyte membrane rafts with actin filaments. J Neurosci Res 81:218225. CrossRef Medline

Tyler WA, Gangoli N, Gokina P, Kim HA, Covey M, Levison SW, Wood TL (2009) Activation of the mammalian target of rapamycin (mTOR) is essential for oligodendrocyte differentiation. J Neurosci 29:6367-6378. CrossRef Medline
Wahl SE, McLane LE, Bercury KK, Macklin WB, Wood TL (2014) Mammalian target of rapamycin promotes oligodendrocyte differentiation, initiation and extent of CNS myelination. J Neurosci 34:4453-4465. CrossRef Medline

Xu X, London E (2000) The effect of sterol structure on membrane lipid domains reveals how cholesterol can induce lipid domain formation. Biochemistry 39:843-849. CrossRef Medline

Zuchero JB, Fu MM, Sloan SA, Ibrahim A, Olson A, Zaremba A, Dugas JC, Wienbar S, Caprariello AV, Kantor C, Leonoudakis D, Leonoudakus D, Lariosa-Willingham K, Kronenberg G, Gertz K, Soderling SH, Miller RH, Barres BA (2015) CNS myelin wrapping is driven by actin disassembly. Dev Cell 34:152-167. CrossRef Medline 